\title{
Mini-Publics and Deliberative Constitutionalism
}

\author{
Stephen Elstub ${ }^{1}$ and Gianfranco Pomatto ${ }^{2}$
}

\section{Introduction}

This chapter considers how ordinary citizens deliberate about constitutional norms in mini-publics. This is becoming a topic of increasing pertinence, ${ }^{3}$ particularly in light of the emergence of democratic $^{4}$ and deliberative ${ }^{5}$ constitutionalisms. Democratic constitutionalists want to increase citizen participation in the constitutional process, while deliberative constitutionalists want to promote communicative interaction based on arguing in constitutional processes. Elster, ${ }^{6}$ a key protagonist of this latter approach, advocates a set of normative criteria for the optimal deliberative constituent assembly, which he suggests should be an elected assembly. We argue that mini-publics, assembled through sortition, can meet Elster's normative criteria, if employed as constituent assemblies. They can also meet the aims of democratic constitutionalists by enabling a diverse range of citizens to participate in the constitutional process. In sum, mini-publics advance Elster's normative criteria because they are specially convened assemblies that are flexible in size, would not be regulated by the constitution themselves, contain elements of secrecy and publicity, are demographically representative, their location is flexible, and they can precede referendums.

\footnotetext{
${ }^{1}$ Lecturer in British Politics at Newcastle University. His research interests are on deliberative democracy, citizen participation, civil society, public opinion and political communication. He is the author of Towards a Deliberative and Associational Democracy (Edinburgh University Press 2008), editor of Democracy in Theory and Practice (Routledge 2012) and co-editor of Deliberative Democracy: Issues and Cases (Edinburgh University Press 2014). He is also the editor of the journal Representation.

2 Post-doctoral fellow and contract professor in Policy Analysis in the Department of Cultures, Politics and Society, University of Turin in the period 2012-2017. He is currently collaborating with Ires Piemonte, research institute of Regional Administration of Piemonte. His research is on public deliberation and controversial issues and on the communication of public policies.

${ }^{3}$ Bruce Ackerman and James S Fishkin, 'Deliberation Day' (2002) 10(2) Journal of Political Philosophy 129; Alan Renwick, After the Referendum: Options for a Constitutional Convention (Constitution Society, 2014); Andre Bächtiger, Maija Setälä, and Kimmo Grönlund, 'Towards a New Era of Deliberative Mini-Publics' in Kimmo Grönlund, Andre Bächtiger, and Maija Setälä (eds), Deliberative Mini-Publics: Involving Citizens in the Democratic Process (ECPR Press, 2014) 225-246, 238; Min Reuchamps and Jane Suiter, Constitutional Deliberative Democracy in Europe (ECPR Press, 2016)

${ }^{4}$ James Tully, Strange Multiplicity: Constitutionalism in an Age of Diversity (Cambridge University Press, 1995) ('Strange Multiplicity'); James Tully, Public Philosophy in a New Key (Cambridge University Press, 2008) ('Public Philosophy'); Vivien Hart, Democratic Constitution Making (United States Institute of Peace, 2003); Joel Colon-Rios, Weak Constitutionalism: Democratic Legitimacy and the Question of Constituent Power (Routledge, 2012)

${ }^{5}$ John Rawls, A Theory of Justice (Harvard University Press, 1971); Jon Elster, 'Deliberation and Constitution Making' in J Elster (ed), Deliberative Democracy (Cambridge University Press, 1998) 97-122 ('Deliberation'); Stephen L Elkin, 'Thinking Constitutionally: The Problem of Deliberative Democracy' (2004) 21(1) Social Philosophy and Policy 29.

6 'Deliberation', above n 3; 'The Optimal Design of a Constituent Assembly' in Helena Lanmore and Jon Elster (eds), Collective Wisdom: Principles and Mechanisms (Cambridge University Press, 2012) 148-72 ('The Optimal Design').
} 
Indeed, mini-publics are increasingly used in constitutional processes in liberal democracies. ${ }^{7}$ However, there has been a lack of research carried out on the quality of deliberation that occurs on constitutional issues in mini-publics. To fill this gap, this chapter considers primary data from two citizens' juries in Italy on the federal reform of the Italian state. The project adopted a mixedmethods approach including pre- and post-questionnaires submitted to the jurors; in depth interviews with jurors after the conclusion of the process; participant observation throughout the process; and analysis of the speech acts of the jurors. The primary focus of the analysis is on the extent to which the discussions were respectful, balanced, justified, and focused on the common good, as these are the deliberative norms prioritised in constitutional debates by Elster. ${ }^{8}$

The chapter proceeds in four sections. Firstly, the emergence of democratic and deliberative constitutionalisms is detailed and related to mini-publics. The case is made that constitutional minipublics present an important opportunity for citizens to participate deliberatively in the constitutional process. The next section introduces the case studies. The third section provides an analysis of the extent to which citizens' juries successfully promoted the selected deliberative norms. We conclude by arguing that the citizens' juries indeed have the potential to combine democratic and deliberative constitutional approaches. However, we raise important caveats and suggest an agenda for future research in this area.

\section{Combining Democratic and Deliberative Constitutionalisms through Mini-Publics}

For consistency, we follow Elsters' definition of 'constitution'. He suggests that there are three related meanings: 'First, many countries have a set of laws collectively referred to as "the constitution". Second, some laws may be deemed "constitutional" because they regulate matters that are in some sense more fundamental than others. And third, the constitution may be distinguished from ordinary legislation by more stringent amendment procedures. ${ }^{9}$ We interpret constitution broadly here, relating to all three senses.

There are numerous approaches advocated and practiced in relation to the formation of constitutions, with varying democratic credentials, ${ }^{10}$ but a focus on democratic processes of constitutional formation and amendment seems to be on the increase, in theory and practice. Of particular importance to the focus here are democratic constitutionalism, which considers citizen participation essential, ${ }^{11}$ and deliberative constitutionalism, which focuses on the deliberative quality of the process. ${ }^{12}$ Here we argue that mini-publics have the potential to combine both these approaches if used as constituent assemblies. They recruit a diverse range of citizens and thereby promote democratic constitutionalism. They promote deliberative constitutionalism by meeting Elster's ${ }^{13}$ normative criteria for a constituent assembly.

\footnotetext{
${ }^{7}$ Reuchamps and Suiter, above n 1.

8 Ibid.

9 Jon Elster 'Forces and Mechanisms in the Constitution-Making Process' (1995) 45, Duke Law Journal, 366.

${ }^{10}$ Elster, 'Deliberation', above n 3, 98.

${ }^{11}$ Tully, Strange Multiplicity and Public Philosophy, above n 2; Hart, above n 2; Colon-Rios, above $n 2$.

12 Rawls, above n 3; Elster, 'Deliberation', above n 3; Elkin, above n 3.

13 (1998)
} 
Starting from a critique of parliamentary sovereignty and the reliance on elected constitutional assemblies, democratic constitutionalists instead move to advocate a 'participatory constituent process' for dealing with constitutional issues. They suggest that such an approach is normatively superior as it enables citizens to exercise power over their foundations, providing a sense of 'ownership' and thereby representing an 'act of completion' or 'a final act of closure'. ${ }^{14}$ The formation of the Brazilian constitution is seen as an effective practical example of this approach. ${ }^{15}$ In contrast, 'ironically, older nations in the western liberal tradition from which such calls have come have not often themselves extended the idea of democratic governance to constitutionmaking'. ${ }^{16}$ This seems to be changing in recent times, and there have been numerous methods advocated to institutionalise a 'participatory constituent process'. ${ }^{17}$ One form of institution being increasingly advocated for its ability to deliver a 'participatory constituent process' is the minipublic. ${ }^{18}$

Citizens are recruited on to mini-publics through either random or stratified sampling in order to achieve to achieve a representataive or diverse sample of the population. The citizens are then assembled to become informed and discuss a topical issue. There are a varitey of types of minipublic including deliberative polls, citizens' assemblies, planning cells, consensus conferences, and citizens' juries. There are important differences between theses types, ${ }^{19}$ but a number of common elements too. Participants are often remunerated, the discussions are facilitated, and experts provide evidence and information and are then questioned by the participants. ${ }^{20}$ They are also primarily consultative as "rarely does the mini-public itself share sovereignty over the decision at hand" ${ }^{21}$ although there are some significant exceptions. ${ }^{22}$ Our cases considered here are citizens' juries which use a smaller sample of citizens and requires them to produce a collective recommendation following deliberation.

Mini-publics have a strong conceptual, empirical, and historical relationship with deliberative democracy. ${ }^{23}$ For this reason they are also often considered to be key institutions for delivering deliberative constitutionalism. The central premise of this approach is that 'deliberation is to be the

\footnotetext{
${ }^{14}$ Hart, above n 2, 2.

${ }^{15} \mathrm{~J}$ B Herkenhoff, $A B C$ da Cidadania. In Verdade no Brasil e no (1996), dhnet.org.br/abc/herkenhoff/

${ }^{16}$ Hart, above $\mathrm{n} 2$; see also Renwick, above $\mathrm{n} 1$.

${ }^{17}$ Michele Brandt, Constitutional Assistance in Post-Conflict Countries. The UN Experience: Cambodia, East Timor and Afghanistan (UNDP, 2005).

${ }^{18}$ Ackerman and Fishkin, above n 1; Mark E Warren and Hilary Pearse (eds), Designing Deliberative Democracy: The British Columbia Citizens' Assembly (Cambridge University Press, 2008); Patrick Fournier et al, When Citizens Decide: Lessons from Citizen Assemblies on Electoral Reform (Oxford University Press, 2011); Bächtiger et al, above n 1, 238; Renwick, above n 1; Helena Landemore, 'Inclusive Constitution-Making: The Icelandic Experiment' (2015) 23(2) The Journal of Political Philosophy 166; Didier Caluwaerts and Min Reuchamps, 'Generating Democratic Legitimacy through Deliberative Innovations' (2016) 52(1) Representation 13; Reuchamps and Suiter, above n 1; J Suiter, David Farrell, and Clodagh Harris, 'The Irish Constitutional Convention: A Case of "High Legitimacy"?' in Min Reuchamps and Jane Suiter (eds), Constitutional Deliberative Democracy in Europe (ECPR, 2016) 33-52.

${ }^{19}$ For an overview see Stephen Elstub, 'Mini-Publics: Issues and Cases' in Stephen Elstub and Peter McLaverty (eds), Deliberative Democracy: Issues and Cases (Edinburgh University Press, 2014) 166-88.

${ }^{20}$ Ibid.

${ }^{21}$ Robert E. Goodin, Innovating Democracy: Democratic Theory and Practice after the Deliberative Turn, (Oxford University Press 2008) 12.

${ }^{22}$ Elstub, above n 19.

${ }^{23}$ Ibid.
} 
basis for lawmaking'. ${ }^{24}$ In Elster's seminal work he claims that 'deliberation is more important in constitution making than in ordinary legislation'. ${ }^{25}$ A constitution determines the nature of the political system itself, has an indefinite future, and deals with complex issues. ${ }^{26}$ Furthermore, 'deliberation about constitutions... requires a deliberative setting' $\cdot{ }^{27}$ Of primary importance here is interaction based upon arguing rather than bargaining. Elster goes on to suggest that there are a number of factors that help determine the extent to which a constituent assembly is orientated towards the arguing, rather than bargaining, end of this continuum. These include its size, levels of publicity, the presence of force, and the level of self-interest of the participants.

Following a review of numerous constitution-making processes, throughout history and the world, Elster ${ }^{28}$ argues that an optimal constitution-making process would be hourglass-shaped, 'with widely open consultative moments upstream and downstream of the drafting, through popular referenda and consultations, but a tiny waist, corresponding to the exclusive and closed moment of actual writing, in which a limited number of drafters are preserved from the passions and pressures of the outside world'. ${ }^{29}$ Therefore the hourglass constitutional sequence proposed by Elster ${ }^{30}$ would include a large public and open debate on values; election of delegates to the constituent assembly; a closed and private debate amongst these representatives to draft the constitution; public consultation and debate to amend the draft, and a referendum to ratify the constitution. He implicitly acknowledges, therefore, the arguments from the democratic constitutionalists that popular participation in the formation of a constitution enhances the legitimacy and stability of the process and resulting document, while maintaining that a representative and deliberative process is also required to further enhance legitimacy. It is the design of the constituent assembly specifically that is our focus here, as opposed to the broader process. It is at this vital part of the process, in Elster's vision, ${ }^{31}$ that citizens are excluded, as he believes that constitutional assemblies should be elected through a proportional system. Elster's point is not necessarily that elections can make the constituent assembly accountable to the public, as he suggests this can be provided by the referendums he wants to use to ratify constitutions. ${ }^{32}$ Rather, it is to ensure the constituent assembly is representative of the public. ${ }^{33}$ In contrast, we argue that mini-publics, which engage a random or stratified sample of citizens, are descriptively representative of the public. They can make an important contribution to moving a constitutional process towards a combination of both democratic and deliberative constitutional approaches, as they enable a diverse range of citizens to deliberate together on constitutional issues, in a setting conducive to the promotion of key deliberative norms. Indeed, in his discussion the bureaux, randomly formed subcommittees used in the French constitutional process of 1789 and 1848, Elster ${ }^{34}$ acknowledges bodies formed through sortition can be deliberatively superior to elected ones.

\footnotetext{
${ }^{24}$ Elkin, above n 3, 39.

${ }^{25}$ Elster, 'Deliberation', above n 3, 118.

${ }^{26}$ Elster, 'The Optimal Design', above n 4, 148.

${ }^{27}$ Elster, 'Deliberation', above n 3, 105.

${ }^{28}$ Elster, 'Deliberation', above n 3, and 'The Optimal Design', above n 4.

${ }^{29}$ Landemore, above n 17, 167

30 'The Optimal Design', above n 4.

31 'The Optimal Design', above n 4.

32 'The Optimal Design', above n 4, 154.

${ }^{33}$ Elster, 'Deliberation', above $\mathrm{n} 3$.

34 Ibid 108-109.
} 
Elster ${ }^{35}$ concludes his discussion by setting out normative criteria for the 'optimal deliberative setting' for a constitution-making process. While Elster favours elected constitutional assemblies ${ }^{36}$ as best meeting these criteria, we argue that mini-publics, assembled through sortition, can also satisfy this standard. Elster's ${ }^{37}$ design features for the 'optimal design', which he considers most likely to 'create the optimal conditions' for 'genuinely impartial deliberation about the common good', include the following:

> Size: Elster argues that bargaining can only occur in small assemblies and that 'in large fragmented assemblies interaction must take the form of arguing' ${ }^{38}$ In order to ensure quality deliberation in the process Elster ${ }^{39}$ advocates for the constituent assembly to be limited in participants (50-100) to avoid strategic behaviour and free-riding. This target is perfectly achievable for mini-publics. For example, deliberative polls tend to have a 130-500 sample, citizen assemblies 100-160 participants, and citizens' juries 12-25. ${ }^{40}$ However, Elster ${ }^{41}$ further clarifies that 'the larger and the more diverse the population, the more delegates are needed to ensure a broadly representative assembly.' Again the use of sampling to form mini-publics can accommodate this, a capacity that is especially significant given that diversity (of the assembly) is seen as essential by Elster ${ }^{42}$ if epistemic benefits of deliberation are to be secured.

$>$ Specially convened assemblies: Elster ${ }^{43}$ highlights that 'when a body such as parliament is involved in shaping the constitution that among other things is to regulate the role of that body, it may have a tendency to write an important role for itself into the constitution.' He argues that this can be mitigated if the constitutional assembly is specially convened. Mini-publics meet this criterion as they are usually issue-specific and dissolved as soon as the issue has been deliberated; ${ }^{44}$ this would be the case with a mini-public acting as a constitutional assembly. Therefore, even if the resulting constitution sets out a significant role for mini-publics in general, this would not include the specific mini-public(s) used to assist in the drafting of the constitution.

$>$ Not regulated by the constitution themselves: This relates directly to the 'specially convened assemblies' criteria. Elster states that 'other institutions or actors whose behaviour is to be regulated by the constitution ought not to be part of the constitution-making process. ${ }^{45}$ Again, as the mini-public(s) acting as the constitutional assembly will be dissolved after the constitution is ratified, their activities would not be subject to control by the constitution itself, even if subsequent mini-publics would be. There is still the danger that the citizens participating in the mini-public would be regulated by the constitution, and could therefore create rights or immunities that would inure to their benefit. However, this would be ameliorated by the use of

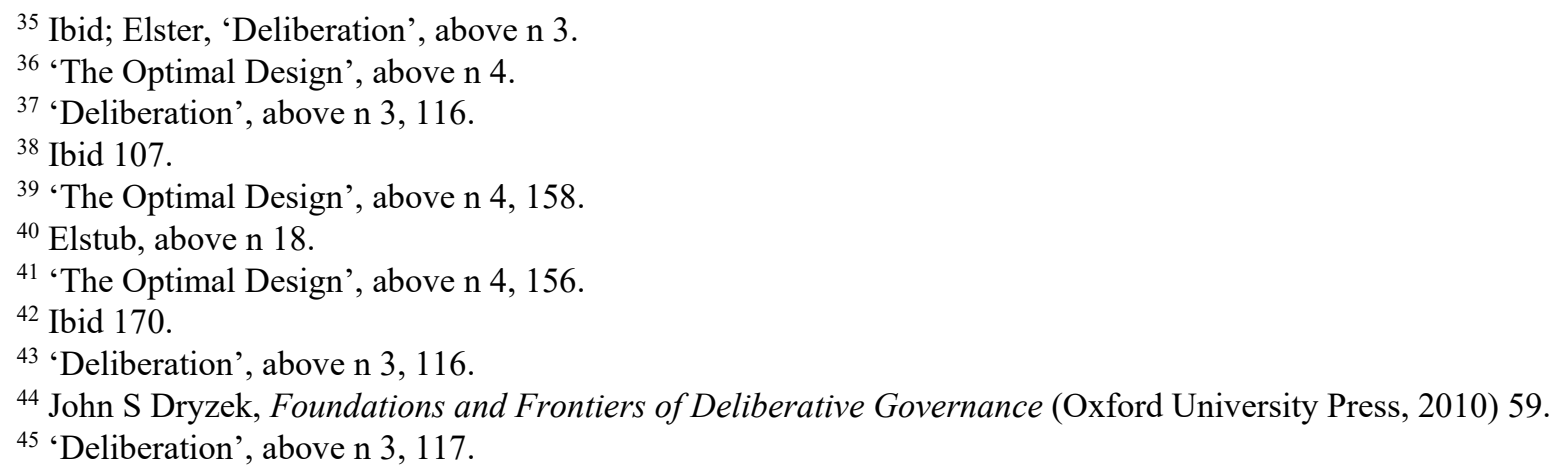


sortition to select the citizen participants as they would be diverse in their interests and more impartial.

$>$ Combine elements of secrecy and publicity: On the one hand Elster ${ }^{46}$ argues that conducting constitutional discussions in public reduces the occurrence of self-interested language and bargaining and enhances reason giving due the civilising force of hypocrisy: 'the presence of a public makes it especially hard to appear motivated merely by self-interest. Even if one's fellow assembly members would not be shocked, the audience would be' ${ }^{47}$ Similarly, in order to encourage members of a constituent assembly to engage in meaningful deliberation Elkin ${ }^{48}$ argues that 'lawmakers must be given the opportunity to be seen to deliberate.' On the other hand an audience decreases the likelihood of impartial motives by increasing passionate ones, due the effectiveness of rhetoric on the audience, and further decreases the chance of preference change in light of the better arguments. Elster consequently concludes that the constitutional drafting process should include deliberations operating in secret with those made public. ${ }^{49}$ Again mini-publics can be designed to meet this criterion, and often combine secret deliberations with those publicly broadcast. Indeed this is a common feature of deliberative polls. $^{50}$

Demographically representative: Despite favouring elected constitutional assemblies, Elster ${ }^{51}$ is himself critical of electoral systems that result in assemblies that are significantly limited in the extent to which they are demographically representative of the citizenry. However, he maintains that this problem can be addressed by the implementation of proportional electoral systems. ${ }^{52}$ In contrast, mini-publics utilise random or stratified sampling to achieve a 'deliberative microcosm' of the population or at least a 'demographically diverse' sample. Each citizen has an equal chance of being selected; consequently the system is useful for achieving descriptive representation, to an even greater extent than proportional electoral systems. ${ }^{53}$ Indeed, in reviewing the Icelandic constitutional process Landemore makes the case for the superiority of randomly sampled constitutional assemblies over elected ones: 'the fact that citizens who were ultimately elected had to run a political campaign in order to attract votes turned them into professional politicians, or at least ensured that only those acting like professional politicians would be elected, thus contradicting the whole premise of having regular citizens onboard the Constitutional Assembly.' ${ }^{54}$ Elster himself reports that in the French constitutional assemblies of 1789 and 1848 the bureaux had a random composition, which promoted impartiality and thereby deliberation over bargaining. ${ }^{55}$ Although not advocating the use of mini-publics himself in the constitutional process, Elkin highlights that

\footnotetext{
46 'Deliberation', above n 3; 'The Optimal Design', above n 4.

47 'Deliberation', above n 3, 111.

${ }^{48}$ Above n 3, 52.

49 'Deliberation', above n 3, 117. It should, however, be noted that more recently Elster (in 'The Optimal Design', above n 4) has revised his opinion, suggesting that the whole constituent assembly process should proceed behind closed doors to encourage participants to change their mind in light of the best reasons offered.

${ }^{50}$ James Fishkin and Robert C Luskin, 'Broadcasts of Deliberative Polls: Aspirations and Effects' (2005) 36 British Journal of Political Science 184.

51 'Deliberation', above n 3.

52 Ibid 99.

${ }^{53}$ Elstub, above n 18.

${ }^{54}$ Above n 17, 186.

55 'Deliberation', above n 3, 109.
} 
'the citizens of a republican regime must have the experience of deliberating and struggling over the content of the public interest themselves if they are to judge the inclinations and capacities of their lawmakers. There is, however, good reason to suppose that the ability to make the necessary judgments about lawmakers is not to be found widely distributed amongst citizens in the absence of experiences that promote it. ${ }^{56}$ Elkin continues to argue that observing others deliberating is not an adequate replacement for participating in it oneself. Mini-publics enable a diverse set of citizens to engage in such deliberation, and if used more widely and regularly, the experience of engaging in deliberation amongst a citizenry could be effectively enhanced.

$>$ Flexible location: Concerned that constituent assemblies can be disrupted by mass demonstrations, Elster ${ }^{57}$ suggests that the assembly should not be held in any major city. Again, the flexibility of mini-publics is a strength here: as they are specially convened, they can be held in any location deemed suitable for the process, providing the travel and accommodation costs of the citizen participants can be covered. However, these costs would also have to be met for elected representatives.

> Can precede referendums: there are several examples of mini-publics preceding referendums in constitutional processes (for example in Iceland ${ }^{58}$ ) and in the citizens' assemblies in British Columbia and Ontario they were used to determine the referendum options themselves. ${ }^{59}$ Moreover, MacKenzie and Warren's evidence from the British Columbia Citizens' Assembly suggests that mini-publics could be 'trusted information proxies' for the public when deciding how to vote in a referendum, precisely because they are made up of 'people like them.' ${ }^{60}$

In recent times mini-publics have played important roles in constitutional processes in Canada, ${ }^{61}$ the Netherlands, ${ }^{62}$ Iceland, ${ }^{63}$ Belgium, ${ }^{64}$ and Ireland. ${ }^{65}$ Research on these mini-publics has significantly advanced our understanding of the potentials and pitfalls of using mini-publics in constitutional processes. However, to date, there has been little research on the quality of deliberation in minipublics considering constitutional issues. Although there have been important studies on the deliberative quality occurring in mini-publics more generally, ${ }^{66}$ these were not specifically addressing constitutional issues. For Elster it seems apparent that certain norms of deliberation are more important in constitutional discussions than others. In sum, Elster thinks it is essential to have

\footnotetext{
${ }^{56}$ Elkin, above n 3, 54.

57 'Deliberation', above n 3, 117.

${ }^{58}$ Landemore, above $\mathrm{n} 17$.

${ }^{59}$ Fournier et al, above n 17.

${ }^{60}$ Michael K MacKenzie and Mark E Warren, 'Two Trust-based Uses of Minipublics in Democratic Systems', in John Parkinson and Jane Mansbridge (eds), Deliberative Systems: Deliberative Democracy at the Large Scale (Cambridge University Press, 2012) 95-124.

${ }^{61}$ Warren and Pearse, above n 17; Fournier et al, above n 17; Caluwaerts and Reuchamps, above n 17.

${ }^{62}$ Fournier et al, above n 17; Caluwaerts and Reuchamps, above n 17.

${ }^{63}$ Landemore, above n 17.

${ }^{64}$ Caluwaerts and Reuchamps, above $\mathrm{n} 17$.

${ }^{65}$ Suiter et al. 2016; Caluwaerts and Reuchamps ibid.

${ }^{66}$ Alice Siu, Look Who's Talking: Examining Social Influence, Opinion Change and Argument Quality in Deliberation (PhD Thesis, Stanford University, USA, 2009); David Sanders, 'The Effects of Deliberative Polling in an EU-Wide Experiment: Five Mechanisms in Search of an Explanation' (2012) 42(3) British Journal of Political Science 617; Marlene Gerber et al, 'Deliberative and Non-Deliberative Persuasion: Mechanisms of Opinion Formation in EuroPolis' (2014) 15(3) European Union Politics 410.
} 
'genuinely impartial deliberation about the common good.' ${ }^{67}$ To achieve impartiality there must be respect and balance to the discussions. To be genuinely deliberative participants must justify their preferences with reasons, ${ }^{68}$ and should be orientated towards promoting the common good. ${ }^{69}$ Consequently, in order to advance our understanding of whether mini-publics can indeed meet the criteria of being the 'deliberative setting' Elster considers so essential for constitutional assemblies, while at the same time enabling the citizen participation demanded by democratic constitutionalists, we analyse the extent to which citizens' juries on Federal reform in Italy successfully promoted respectful and balanced reasoning on the common good. We now move to introduce our case studies in more detail.

\section{Citizens' Juries on the Federal Reform of the Italian State}

This section presents the salient details of the citizens' juries on the federal reform of the Italian State and the methodology employed to study them. First of all, in order to better comprehend the context in which these juries took place, we briefly retrace the structure of the Italian State and its evolution in the last few decades.

The Italian State is structured in 20 Regions that have had limited functions since their creation, except for five of them (the 'Special Statutes Regions') that obtained a wide legislative and fiscal autonomy due to historical-geographic or ethno-linguistic reasons. The consistent electoral support gained by an autonomist party in the North of the country since the 1992 election - the Northern League Party - has put federal reform on the national agenda for a considerable time, receiving attention both by main right wing and left wing parties.

The most controversial aspect of the debate refers to the fiscal implications of federalism, due to the fact that Italy has among the most relevant internal socio-economical cleavages in Europe. The fiscal redistribution from the Centre-North of the country towards the South has traditionally been impressive and the federal reform of the State could change this consolidated equilibrium. Indeed, the main declared purpose of the North League Party in seeking federal reform has continuously been to reduce the level of this redistribution.

A constitutional reform proposal that was approved by a centre-left coalition Parliament and later confirmed by a national referendum in 2001 initiated the transition toward a federalist structure of the State, devolving some legislative power to Regions and recognizing a proper fiscal power for them. In 2009 a large majority in the Parliament approved a general law (law 42/2009) to concretely foster the fiscal power for Regions recognised by the 2001 Constitutional reform. However, the implementation of the reform could start only after the approval of eight other highly technical decrees by the Government in the next two years and it therefore proceeded very slowly. In 2016 another constitutional reform introducing a Senate elected by regional councils was approved by the Parliament but rejected by referendum.

Therefore federalism is an ongoing process that is far from resolution, even after more than 15 years of prominence on the Italian political agenda. As part of the Biennial Festival of Democracy, a

\footnotetext{
67 'Deliberation', above n 3, 116.

${ }^{68}$ Elster, 'Deliberation', above n 3, 101; 'The Optimal Design', above n 4, 150; Elkin, above n 3, 42.

${ }^{69}$ Elster, 'The Optimal Design', above n 4, 150.
} 
cultural event supported by the City Council of Turin and several not for profit foundations, four citizens' juries on the federal reform of the State in three different cities were organised: two in Turin (North Italy), one in Florence (Centre Italy) and one in Lamezia Terme (South Italy) in the period December 2010-April 2011. The overall project was coordinated by the University of Turin and supervised by a Guarantee Board composed of 11 experts with diverse views on federalism. The project was launched by the organisers in an open seminar on the 3rd December 2010 when a first report was circulated. It illustrated what federalism is in general terms; what the main reforms approved or under discussion in Italy have been; and the major arguments in favour or against the reform. It was then delivered to the randomly-selected jurors of the first jury in Turin. Moreover this first report was made freely available via 130,000 copies in Turin with the newspaper $L a$ Stampa in the 8th April 2011 issue. $^{70}$

After this first jury, a second more extensive document illustrating different scenarios for the federal reform in Italy was produced by the organisers and delivered to the jurors in the second jury of Turin. This second report was also delivered to the participants in the other two juries. ${ }^{71}$ The final recommendations of the juries were presented and discussed in a public seminar in Turin, on $16^{\text {th }}$ April 2011. Both the reports and final recommendations of all the juries have been published on the related website which, in the period December 2010-April 2011, received about 4,000 individual visits.

The analysis presented in this article regards the two citizens' juries in Turin. ${ }^{6}$ The first jury was held on the $10^{\text {th }}-11^{\text {th }}$ December 2010 and included 25 randomly selected jurors and 7 witnesses (all of them were experts from universities or other research institutions). The second jury was held on the $4^{\text {th }}-5^{\text {th }}$ March 2011 and included 42 randomly selected jurors ${ }^{72}$ and 8 witnesses $(5$ experts and 3 political actors). The 'process tracing' methodology, also called 'causal-process observation', was adopted. ${ }^{73}$ It aims to explain what really happened during the implementation process of the juries on the basis of data collected through a combination of several methods:

- Direct observation of all plenary sections and 8 discussion sessions of both juries (over 22 sessions).

- Transcription of 15 discussion sessions from both juries. This produced 1,093 speech acts of jurors which were coded through 11 items presented in the Table $1^{74}$ : the length of each speech act has been measured; the arguments (where present) have been identified and their quality has been evaluated; the general orientation toward federalism (when attributable) has been signalled. Moreover, we refer to the analysis by Ravazzi ${ }^{75}$ about the 570 speech acts of facilitators.

\footnotetext{
${ }^{70}$ Other articles covering the conclusion of the jury are: Emanuela Minucci, Fisichella, Ricolfi e Zagrebelsky "Quale federalismo per l'Italia?, La Stampa, 16/04/2011, p.64 and Letizia Tortorello, Partono da Piazza Carignano le prove generali di federalismo, La Stampa, 17/04/2011, p.65.

${ }^{71}$ The other two juries took places on the 4th April 2011 (Florence) and on the 8th-9th April 2011 (Lamezia Terme). The case study has been realised inside wider research on the quality of deliberation directed by Luigi Bobbio, and the overall results of the research have been published (Bobbio, 2013).

7215 of them had just taken part to the first jury, while other 27 jurors were new participants.

${ }^{73}$ David Collier, 'Understanding Process Tracing' (2011) 4 Political Science and Politics 823.

${ }^{74}$ In order to test the intercoder agreement, a subset of the speech acts has been recoded: the correspondence of codification for each item was equal to, or higher than, $90 \%$.

75 Stefania Ravazzi 'Facilitare la deliberazione. Il ruolo dei professionisti', in Luigi Bobbio (ed.), La qualità della deliberazione, (Carocci, 2013) pp. 147-78.
} 
- Two questionnaires for jurors, elaborated by the University of Siena, were collected. One before the beginning and one after the conclusion of juries. Table 2 presents the survey items that formed the basis of our analysis here. The first three items were included only in the questionnaire after the conclusion of the juries because they concerned the issues of respect between jurors and the balance of arguments made in the jury discussions. The fourth items were included both in the questionnaires before the beginning and after the juries in order to measure the opinion change toward federalism of jurors.

- A subsample of 16 jurors were interviewed in depth after the conclusion of the process. These jurors were asked to express their opinions and perceptions about the relationships established with the other jurors, the facilitators and the experts, the development of the discussions, and the final results of the jury.

Table 1. The analysis of the speech acts of jurors

Items Modalities

Length of speech acts Number of characters:......

Pertinence $\quad$ 0) No; 1) Yes

Level of inference of argument 0 ) no argument in the speech act 1) argument with incomplete inference 2) argument with complete inference

Level of generality of argument 0) no argument in the speech act 1) argument referring to personal interest 2) argument referring to group interest 3) argument referring to general interest or marginalized groups interest

Orientation toward federalism $\quad$-2) very much against -1) quite a lot against 0 ) neutral or not attributable 1) quite a lot in favour 2) very much in favour

Table 2. The questionnaires for jurors

\begin{tabular}{lll}
\hline Items & Modalities & Questionnaire
\end{tabular}

My fellow jurors have respected what I said

level of agreement with the

even when they did not agree with me

statement on a scale $0-10$

After the juries 
During the discussion I have had extensive opportunities to express my opinions

Some participants have been more active than me in the discussion?

Piedmont should be able to decide autonomously how to satisfy the needs of its residents level of agreement with the

After the juries

statement on a scale $0-10$

Not at all/a little

Somewhat After the juries

Quite a lot/very much

-2) very against -1) fairly against

Before and after

0) abstension 1) fairly in favour 2)

much in favour the juries very

\section{Constitutional Deliberation in the Citizens' Juries}

In this section we present and discuss the findings derived from our analysis that refer to the four privileged deliberative norms: the level of respect, the balance, degree of reasoning and the focus on the common good within the jury discussions.

\section{Respect}

The observation of the process evidenced a high level of respect among jurors. No episodes were observed in which verbal interactions among jurors were disrespectful, even where there was strong disagreement. The highly respectful climate of the discussion was also strongly confirmed by jurors themselves through the anonymous answers to the final questionnaire and in the in-depth interviews to a subsample of them. As is shown in Table 3, jurors perceived a high level of respect even in cases of disagreement. Along a scale $0-10$ the average level of respect perceived by jurors is over 8 and the standard deviation is low, less than 2. In the sixteen in-depth interviews none of the jurors referred to disrespectful episodes in which they were involved or observed; moreover several interviewees referred to be particularly impressed by the high level of respect.

Table 3. The perception of jurors about respect

\begin{tabular}{llcl}
\hline & & First jury & $\begin{array}{l}\text { Second } \\
\text { jury }\end{array}$ \\
\hline $\begin{array}{l}\text { My fellow jurors have } \\
\text { respected what I said } \\
\text { even when they did } \\
\text { not agree with me }\end{array}$ & $\begin{array}{l}\text { Average level of agreement with the statement } \\
(0-10)\end{array}$ & 8.9 & 8.4 \\
\cline { 2 - 4 } & $\begin{array}{l}\text { Standard deviation } \\
\text { (Number of answering jurors) }\end{array}$ & 1.4 & 1.6 \\
\hline
\end{tabular}

This highly respectful climate induced jurors to perceive a high level of freedom of expression as is shown by Table 4: the average level of perception of having the opportunity to extensively express one's own opinion is above 8 along a $0-10$ scale and the standard deviation is less than 2 . 
Table 4. The perception of jurors about the freedom of expression

\begin{tabular}{clcl}
\hline & & First jury & \multicolumn{1}{c}{$\begin{array}{c}\text { Second } \\
\text { jury }\end{array}$} \\
\hline $\begin{array}{c}\text { During the discussion I } \\
\text { have had extensive } \\
\text { opportunities to express } \\
\text { my opinions }\end{array}$ & $\begin{array}{l}\text { Average level of agreement with the statement } \\
\text { Standard deviation }\end{array}$ & 8.2 & 8.2 \\
\cline { 2 - 4 } & (Number of answering jurors) & 1.8 & 1.6 \\
\hline
\end{tabular}

Also the interviewees comprehensively confirmed this perception. For example:

At the beginning there was a little embarrassment... as happens among people who do not know each other... but in a short time the embarrassment disappeared. I did not find any barrier to express myself. We were all quite relaxed (I. 6). ${ }^{76}$

The discussion has certainly been open to different positions. I have clearly noticed that there were two main opposing ideas... but it has really been a free and peaceful discussion (I. 4). ${ }^{77}$

\section{Balance}

The observers suggested that there was an unbalanced participation in the discussions: some jurors appeared particularly active, intervening several times in each session and with longer speech acts where others seemed to be more passive. The more active participants were also the more educated. The existence of an asymmetry in the active participation in the discussion is confirmed both by the questionnaire after the conclusions of the juries and the analysis of the speech acts.

As can be seen in Table 5, almost half of the jurors recognised that some other participants had been more active in the discussion. Table 6 provides evidence that the arguments are concentrated in the minority of the speech acts that are longer than 400 characters ${ }^{78}$ and there is a moderate positive correlation between the length of speech acts and the recourse to argumentation $(r=0,52)$. In other words, the jurors who spoke more were reasonably more able to influence the development of the discussion not only because of the time they used, but also because they were able to communicate in a more complex way.

\footnotetext{
${ }^{76}$ Middle-aged male juror from Jury 1 interviewed in Torino, 20/12/2010.
}

\footnotetext{
${ }^{77}$ Middle-aged female juror from jury 1 interviewed in Torino, 21/12/2010

${ }^{78}$ The observed differences are statistically significant (qui-squared test: $\chi 2=339 ; \mathrm{p}<0.01$ ).
} 


\begin{tabular}{|c|c|c|c|}
\hline & & $\begin{array}{c}\text { First jury } \\
\text { (N. of jurors) }\end{array}$ & $\begin{array}{l}\text { Second } \\
\text { jury } \\
\text { (N. of } \\
\text { jurors) }\end{array}$ \\
\hline \multirow{5}{*}{$\begin{array}{l}\text { Some participants } \\
\text { have been more active } \\
\text { than me in the } \\
\text { discussion? }\end{array}$} & Not at all/a little & 4 & 10 \\
\hline & Somewhat & 4 & 8 \\
\hline & Quite a lot/very much & 10 & 21 \\
\hline & (Number of answering jurors) & (18) & (39) \\
\hline & (Number of not answering jurors) & (4) & (3) \\
\hline
\end{tabular}

Table 6. The length of speech acts of jurors

\begin{tabular}{lccc}
\hline & $\begin{array}{c}\text { Number of } \\
\text { speech acts } \\
\text { without } \\
\text { (N. of characters) }\end{array}$ & $\begin{array}{c}\text { Number of speech } \\
\text { act with argument }\end{array}$ & $\begin{array}{c}\text { Total number } \\
\text { of speech } \\
\text { acts }\end{array}$ \\
\hline$<200$ & 769 & 27 & 796 \\
$200-400$ & 100 & 41 & 141 \\
$>400$ & 66 & 90 & 156 \\
Tot & 935 & 158 & 1093 \\
\hline
\end{tabular}

On the one hand this imbalance could be evaluated in negative terms, because any kind of imbalance could actually be considered undesirable from a deliberative perspective. On the other hand, however, it could be considered that inside real mini-publics it is not possible to cancel all the asymmetries. Consequently, a certain degree of imbalance in active participation in the discussion that is referable to pre-existent diversities in education, social skills and personal attitudes of jurors is quite acceptable. This is particularly the case if there is a high level of respect, a wide perception of freedom of expression and the avoidance of other more relevant kinds of undesirable influences such as the manipulation by facilitators, the conformist polarization of jurors towards the preexisting majoritarian orientation and the partisan influence by witnesses. Indeed, this is what was found in the citizens' juries in Turin.

For example, as we have just highlighted above, the respect among jurors has been high and also the perception of a freedom of expression was widespread. The analysis of the speech acts of facilitators clearly demonstrates that for the most part they repeated or summarised statements of jurors, recalled rules, times and topics under discussion, asked jurors to argue, and stimulated more passive jurors to intervene. They did not force jurors towards a positive view about federalism nor toward a negative view of the constitutional issues being discussed. ${ }^{79}$

\footnotetext{
${ }^{79}$ Ravazzi, 'Facilitare la Deliberazione' note 73 above $147-78$.
} 
There is much evidence that testifies that polarization did not take place, even if at the beginning of the two juries there was a majority of jurors in favour of federalism, as you can see from Table 7: 34 jurors supporting federalism while only 4 jurors contesting it and another 14 uncertain or not answering. At first, as you can see from Table 8, the majority of speech acts in all the sessions are not oriented and therefore, for the most part, the discussion could not produce a pressure toward a univocal orientation. Secondly, there is no significant difference about the length of the speech acts ${ }^{80}$ and the presence of argument ${ }^{81}$ between speech acts supporting and opposing federalism and it confirms the climate of freedom of expression for both sides. Thirdly, the unbalance in the oriented speech acts affected who were in the majority at the beginning and not who was in the minority (119 speech acts opposing federalism against 61 supporting federalism, Table 8) in contrast to what we would expect to find had polarization occurred.

Table 7. The orientation of jurors towards federalism before the beginning of juries

\begin{tabular}{llc}
\hline & & $\begin{array}{c}\text { Number } \\
\text { of } \\
\text { jurors }\end{array}$ \\
\hline Piedmont should be able to decide & Fairly in favour and very much in & 34 \\
autonomously how to satisfy the needs & favour & 4 \\
of & Fairly against and very against & 14 \\
& Abstentions/no answer & \\
& Total* & 52 \\
\hline
\end{tabular}

* jurors of the first jury+new recruited jurors for the second jury

Table 8. Speech acts supporting and opposing federalism and the use of arguments

\begin{tabular}{llll}
\hline & $\begin{array}{c}\text { Number of Speech } \\
\text { acts without } \\
\text { argument }\end{array}$ & $\begin{array}{c}\text { Number of speech act } \\
\text { with argument }\end{array}$ & $\begin{array}{c}\text { Total number of } \\
\text { speech acts }\end{array}$ \\
\hline Supporting federalism* & 31 & 30 & 61 \\
Opposing federalism** & 67 & 52 & 119 \\
Tot. & 97 & 83 & 180 \\
\hline
\end{tabular}

* quite a lot in favour + very much in favour ** quite a lot against + very much against

The witnesses, as evident in several in-depth interviews, played a relevant role in shaping the opinion of jurors. In the first jury all the witnesses were experts from universities or research centres and they had a deep knowledge of the ongoing process of transition towards federalism. Therefore most of them focused the current technical restrictions of such transition rather than exploring the possible long-term future scenarios or the systemic effects of federal reform. In this way they were able to transmit to jurors relevant specific knowledge about the topic, but they also, at the same time, act as a sort of cognitive barrier for the discussion. In order to overcome this overly narrow

\footnotetext{
${ }^{80}$ qui-squared test: $\chi 2=1,6 ; \mathrm{p}=0,45$

${ }^{81}$ qui-squared test: $\chi^{2}=0,8 ; \mathrm{p}=0,36$
} 
perspective the organisers introduced two adjustments for the second jury. Firstly, a new informative document explicitly presenting different future scenarios for a federal reform in which Regions received different degrees of fiscal autonomy, independently from the current restrictions. Secondly, the recruitment of three local political actors with opposite orientation about federalism as witnesses, in order to avoid an excessively technical level of discussion. Of particular importance is that, even if witnesses had an influence on the discussion, there is no evidence to suggest that they influenced the jurors in a univocal and partisan manner.

\section{Reasoning and common good}

The analysis of the speech acts highlights that the communicative interactions among participants have been nuanced: a high level of pertinence and of reference to the common good combined with a varied use of arguments that have generally been incomplete.

The pertinence of a speech act refers to its connection with the general topic under discussion. A speech act is pertinent when its content is connected to the topic and this connection is understandable. The pertinence of speech acts have been high all over the development of the process, as one can see in Table $9(70,2 \%$ of average pertinent speech acts in the first jury and $75,1 \%$ in the second jury). Moreover the reference to common good was almost generalized: $89,2 \%$ of all arguments referred to general interest or to marginalized group interest, whereas only $6,8 \%$ referred to group interest and $4 \%$ to personal interest (Table 10). On the whole these findings clearly support the idea that lay citizens inside a mini-public are enabled to discuss complex topics like federalism with a consistent capacity to focus on the content of the issue, avoiding at the same time a particularistic perspective.

The inference of arguments refers to the cause-effect connections expressed in a speech act. The inference is complete when the links between the supposed causes and effects are explained. The inference is incomplete when a causal relationship is adduced without justifying the connections that give validity to the relationship. Our evidence indicates that the level of inference of arguments was generally incomplete and that the use of argument by participants was not constant, swinging between sessions in which the majority of speech acts contained at least one argument and sessions in which arguments were really rare (Table 9). Two explanations shed light on this phenomenon, each with different implications.

A first explanation focuses on the fact that for a considerable part of the time, the jurors' discussions focused on identifying the questions for witnesses and summarising information received from them. It is therefore perfectly understandable that the use of arguments is low. The purpose of these kinds of communicative interactions among jurors, in fact, is to enhance the shared knowledge on the issue under discussion and it is clearly consistent with the deliberative perspective.

\section{Table 9. Pertinence and argumentation in the speech acts of jurors}

$\begin{array}{lll}\text { Jury } & \text { Session } & \begin{array}{l}\% \text { of pertinent } \\ \text { speech acts }\end{array}\end{array} \quad \begin{aligned} & \% \text { of pertinent speech acts } \\ & \text { with argument }\end{aligned}$




\begin{tabular}{llll}
\hline \multirow{4}{*}{ First jury } & I & $66,7 \%$ & $53,3 \%$ \\
& II & $79,4 \%$ & $51,9 \%$ \\
& III & $55,9 \%$ & $31,6 \%$ \\
& IV & $66,4 \%$ & $16,1 \%$ \\
& V & $77,8 \%$ & $40,5 \%$ \\
& VI & $100,0 \%$ & $6,7 \%$ \\
& Total & $70,2 \%$ & $30,5 \%$ \\
\hline I & $98,8 \%$ & $13,9 \%$ \\
Second jury & II & $93,9 \%$ & $12,9 \%$ \\
& III & $82,0 \%$ & $32,0 \%$ \\
& IV & $51,2 \%$ & $9,1 \%$ \\
& V & $51,5 \%$ & $11,4 \%$ \\
& VI & $68,1 \%$ & $2,2 \%$ \\
& VII & $77,1 \%$ & $3,7 \%$ \\
\hline First + second jury & VIII & $94,9 \%$ & $5,4 \%$ \\
\hline
\end{tabular}

Table 10. Level of inference and level of generality of the pertinent arguments

\begin{tabular}{|c|c|c|c|}
\hline & & $\begin{array}{l}\text { Number of } \\
\text { pertinent } \\
\text { arguments }\end{array}$ & $\begin{array}{c}\% \text { of } \\
\text { arguments }\end{array}$ \\
\hline \multirow{3}{*}{$\begin{array}{l}\text { Level of inference of } \\
\text { arguments }\end{array}$} & Complete & 24 & $16.2 \%$ \\
\hline & Incomplete & 124 & $83.8 \%$ \\
\hline & Tot. & 148 & $100 \%$ \\
\hline \multirow{4}{*}{$\begin{array}{l}\text { Level of generality of } \\
\text { arguments }\end{array}$} & Personal interest & 6 & $4.0 \%$ \\
\hline & Group interest & 10 & $6.8 \%$ \\
\hline & $\begin{array}{c}\text { General interest or marginalised group } \\
\text { interest }\end{array}$ & 132 & $89.2 \%$ \\
\hline & Tot. & 148 & $100 \%$ \\
\hline
\end{tabular}

A second explanation highlights that lay citizens prefer to narrate than to argue; when they argue, they generally use implicit and not well-developed arguments. This raises the issue of the deliberative attitude of participants, suggesting that it cannot be considered natural or be taken for granted. Of particular importance in this regard is the analysis by Ravazzi ${ }^{82}$ on the speech acts of facilitators inside these juries. Her analysis in fact shows that facilitators contributed to enhance the level of the debate in several ways: completing the argument proposed by jurors, highlighting the logic or practical consequences of such statements, or playing the role of devil's advocate. Moreover, it demonstrates that facilitators were able to enhance the use of arguments:

\footnotetext{
${ }^{82}$ Above $n 73$.
} 
approximately $15 \%$ of the speech acts of facilitators involved asking a specific juror to provide a justification: this request was effectively satisfied in the $68 \%$ of cases.

\section{Conclusion}

Elster ${ }^{83}$ favours elected constitutional assemblies to provide 'deliberative settings' in the constitutional process. In contrast, we have argued that mini-publics are well placed to meet Elster's normative criteria for the optimal deliberative setting for a constitution-making process. ${ }^{84}$ Elster ${ }^{85}$ wants the deliberative setting to produce 'genuinely impartial deliberation about the common good'. ${ }^{86}$ To determine whether mini-publics can indeed meet this criteria for a deliberative setting, we have analysed the debates in two citizens' juries on federal reform in Italy around four central deliberative norms: level of respect, overall balance, extent of reasoning and focus on the common good. From our analysis, we found much evidence that the discussions were respectful, balanced and orientated to the common good. However, all things considered the quality of reasoning was not strong. This is an important discrepancy, and not one that should be dismissed lightly if minipublics are to be considered as constituent assemblies.

There are of course further failings of mini-publics that would limit the extent mini-publics should be used as constituent assemblies, in addition to the lack of quality of reasoning that we found. Lafont argues mini-publics are an example of 'elite deliberation' as the views of the citizens that participate in the mini-public are transformed through the process and are no longer representative of those of the broader public excluded from the mini-public. ${ }^{87}$ Consequently, employing minipublics to shape a constitution is either an illegitimate or superfluous process that ultimately requires non-participants to 'blindly defer' to the deliberations of the few who are selected, which 'weakens the feedback loop between political decision-making and actual deliberation in the broader public sphere.' Moreover, Böker and Elstub ${ }^{88}$ argue that as mini-publics are artificially designed and controlled instruments, they potentially contradict the critical, emancipatory edge of deliberative democracy. Nevertheless, we still believe the evidence suggests that mini-publics can play an important role in constitutional processes and help synthesise the democratic and deliberative approaches to constitutionalism. A key challenge is to identify the optimum role for mini-publics in constitution-making, and we hope our evidence has made a contribution here by highlighting their strengths and weaknesses with respect to generating key deliberative norms required in an ideal constitution-making process. Although we have focused on the micro dynamics of mini-publics in our study, these are interlinked with the macro aspects in important ways. ${ }^{89}$

For example, because the discussions in mini-publics are respectful, balanced and orientated to the common good, but lack quality reasoning, we suggest that their role should be reviewing the arguments generated from other parts of the constitutional process, rather than providing these themselves. They could then run alongside an elected constituent assembly, and act as a filter in the

\footnotetext{
83 'Deliberation', above n 3; 'The Optimal Design', above n 4.

${ }^{84}$ Above $\mathrm{n} 3$.

85 'Deliberation', above n 3, 116.

${ }^{86}$ See also Elkin, above n 3, for a similar set of requirements.

${ }^{87}$ Cristina Lafont, 'Deliberation, Participation, and Democratic Legitimacy: Should Deliberative Mini-publics Shape Public Policy?’ (2014) 23(1) Journal of Political Philosophy 40, 48.

${ }^{88}$ Above $\mathrm{n} 57$.

${ }^{89}$ Bächtiger et al, above n 1, 230.
} 
process. In essence, arguments that jurors agreed could not stand the test of publicity, and that they considered were not orientated towards the common good, could then be filtered out by the minipublic (or at least flagged as inadequate, for further discussion in the public sphere and elected constituent assembly). If the mini-public's reasoning here received sufficient media attention and exposure, broader deliberation in the formal and informal public sphere could be generated. ${ }^{90}$ Media reform would though be required to make this viable and desirable due to its current deliberative inadequacies, ${ }^{91}$ but a more routine and embedded use of mini-publics in constitutional processes could also help, where mini-publics could act as intermediaries between actors with competing logics such as citizens, experts, and the media. ${ }^{92}$ Interestingly, Mongolia has recently passed a law requiring the use of deliberative polls in advance of all constitutional amendments. ${ }^{93}$ This represents an ideal environment for further research on these issues.

To further set the agenda for research in this area, it is important to highlight some limitations in our own project. Firstly, we considered citizens' juries. However, larger citizens' assemblies have been more commonly utilised in constitutional processes, and therefore, given that there are some important differences between these types of mini-public, ${ }^{94}$ more research is required on deliberative quality in citizens' assemblies on constitutional issues. Secondly, the Italian citizens' juries subjected to analysis were part of a research project. Although designed to have impact and inform federal debates in Italy, they held no formal institutionalised role. This lack of decisionmaking power could well affect the quality of deliberation and particularly the degrees of balance, respect, reason-giving and focus on the common good, both negatively and positively. We therefore suggest further research on institutionally embedded mini-publics, to see if our findings are replicated.

\footnotetext{
${ }^{90}$ Simon Niemeyer, 'Scaling-Up Deliberation to Mass Publics: Harnessing Mini-Publics in a Deliberative System' in Kimmo Grönlund, Andre Bächtiger, and Maija Setälä (eds), Deliberative Mini-Publics: Involving Citizens in the Democratic Process (ECPR Press, 177), 179.

${ }^{91}$ Lafont, above $\mathrm{n} 88,58$.

${ }^{92}$ Gianfranco Pomatto, 'Deliberative Mini-Publics: The Best is Yet to Come', (2016) 52(2-3) Representation, $239-248$.

93 http://cdd.stanford.edu/2017/mongolias-first-national-deliberative-poll-on-constitutional-amendments/ (last visited 07/07/2017).

${ }^{94}$ Elstub, above n 18.
} 